Research Article

\title{
Diagnostic Value of Fractional Exhaled Nitric Oxide and Small Airway Function in Differentiating Cough-Variant Asthma from Typical Asthma
}

\author{
Yanqi Wang, ${ }^{1}$ Lixuan Zhao, ${ }^{1}$ Fang Chen, ${ }^{2}$ Yufeng Guo, ${ }^{2}$ Hongxia $M a,{ }^{2}$ Baofen Han, \\ Jiang Yi, ${ }^{2}$ and Xiaomei Kong $\mathbb{D}^{2}$ \\ ${ }^{1}$ Shanxi Medical University, Taiyuan, Shanxi 030001, China \\ ${ }^{2}$ Department of Respiratory and Critical Care Medicine, The First Hospital of Shanxi Medical University, Taiyuan, \\ Shanxi 030001, China \\ Correspondence should be addressed to Xiaomei Kong; drkathy8@163.com
}

Received 22 March 2021; Revised 9 July 2021; Accepted 9 August 2021; Published 20 August 2021

Academic Editor: Theodoros I. Vassilakopoulos

Copyright ( 2021 Yanqi Wang et al. This is an open access article distributed under the Creative Commons Attribution License, which permits unrestricted use, distribution, and reproduction in any medium, provided the original work is properly cited.

Purpose. To explore the diagnostic value of fractional exhaled nitric oxide (FeNO), small airway function, and a combined of both in differentiating cough-variant asthma (CVA) from typical asthma (TA). Methods. A total of 206 asthma subjects, including 104 CVA and 102 TA, were tested for pulmonary function, bronchial provocation test and FeNO. The correlation between FeNO, small airway function and other pulmonary indicators was analyzed by single correlation and multiple regression analysis. The receiver operating characteristic (ROC) curve was established to evaluate the diagnostic efficiency of FeNO, small airway function, and their combination and to predict the optimal cut-off point. Results. All the respiratory function parameters and small airway function indicators in TA group were significantly different from those in CVA group, and FeNO value was significantly higher than that in CVA group. In addition, the area under the ROC curve (AUC) was estimated to be 0.660 for FeNO, 0.895 for $\mathrm{MMEF}_{75 \% / 25 \%}, 0.873$ for $\mathrm{FEF}_{50 \%}, 0.898$ for $\mathrm{FEF}_{25 \%}, 0.695$ for Fres, 0.650 for R5-R20, and 0.645 for X5. The optimal cut-off points of FeNO, $\mathrm{MMEF}_{75 \% / 25 \%}, \mathrm{FEF}_{50 \%}, \mathrm{FEF}_{25 \%}$, Fres, R5-R20 and X5, were $48.50 \mathrm{ppb}, 60.02 \%, 63.46 \%, 45.26 \%, 16.63 \mathrm{~Hz}, 0.38 \mathrm{kPa} \cdot \mathrm{L}^{-1} \cdot \mathrm{s}^{-1}$, and -1.32 , respectively. And the AUC of FeNO combined with small airway function indexes $\mathrm{FEF}_{25 \%}$, Fres, R5-R20, and X5 were prior than single indicators. Conclusion. FeNO and small airway function indexes might have great diagnostic value for differentiating CVA from TA. The combination of $\mathrm{FeNO}$ and $\mathrm{FEF}_{25 \%}$, Fres, R5-R20, and X5 provided a significantly better prediction than either alone.

\section{Introduction}

Asthma is a common respiratory disease. Airway hyperresponsiveness, airway inflammation and reversible airflow limitation are the main pathophysiological characteristics of asthma [1]. Cough-variant asthma (CVA) is a subtype of asthma with chronic cough as a single clinical symptom, without wheezing or dyspnea [2]. Typical asthma (TA) is characterized by recurrent wheezing, chest tightness, or cough, often accompanied by reversible airflow limitation, airway hyperresponsiveness, and airway remodeling [3]. As nearly $30 \%$ of CVA will have wheezing, shortness of breath, and other symptoms as the disease progresses and eventually develop into TA, CVA is considered to be the precursor of TA [4]. However, the evolution from CVA to TA has not been fully elucidated. Studies believe that the pathogenesis of CVA is similar to that of TA, which is chronic airway inflammation involving multiple cells [5], and airway inflammation is one of the most common factors that aggravate BHR and cough receptor hypersensitivity [6]. Therefore, it is speculated that CVA will be aggravated to TA due to airway inflammation. In addition, in terms of cell infiltration and inflammatory factor gene expression, TA and CVA seem to have a common inflammation mode [7]. CVA may also have BHR-related persistent coughing with hidden bronchoconstriction without wheezing. The 
development of CVA to TA is also considered a natural process [8]. Therefore, early diagnosis of CVA is very important, and distinguishing CVA from TA may lead to understanding incipiency of the disease. However, CVA diagnosis remains difficult because chronic, nonproductive cough has a wide range of etiologies.

The bronchial provocation test (BPT) is a key method for the diagnosis of CVA, and the diagnosis of CVA should be based on laboratory evidence of bronchial hyperresponsiveness (BHR) and/or therapeutic effects according to the guidelines [9]. However, BHR detection has some risks and limitations in clinical application [10]. Therefore, it is very important to find a new method for the early diagnosis of CVA and distinguish CVA from TA. In recent years, fractional exhaled nitric oxide (FeNO) and small airway function have been widely used in clinical practice due to their noninvasive, simple, and highly repetitive characteristics in evaluating airway inflammation, or airway reactivity [11].

Nitric oxide (NO) is catalyzed by inducible nitric oxide synthase (iNOS) in airway epithelial cells and produced by $\mathrm{L}$-arginine transformation. FeNO is significantly associated with eosinophilic airway inflammation and plays an important role in the cause of chronic cough [12]. In addition, chronic airway inflammation is the essence of asthma, and the number of inflammatory cells in the small airway is significantly higher than that in the air duct and alveolar tissue during its development [13]. Studies have found that small airway function associates with airway reactivity, control level, and severity of asthma [14]. However, it is not clear whether FeNO combined with small airway function can improve the diagnostic value in differentiating CVA from TA. Therefore, the purpose of this study was to explore the clinical value of FeNO combined with small airways function in differentiating CVA and TA by analyzing TA and CVA patients.

\section{Materials and Methods}

2.1. Study Population. A total of 206 subjects in the outpatient service of respiratory and critical care medicine of the First Hospital of Shanxi Medical University from October 2018 to October 2019 participated in the research. The inclusive criteria were as follows: (1) the diagnoses of asthma were in line with the diagnostic criteria in the guidelines for the Global Initiative for Asthma guidelines and Chinese National Guidelines on diagnosis and management of cough: consensus and controversy $[15,16]$, first diagnosed with asthma; (2) >18 years old; (3) without abnormalities on chest X-ray; (4) without treatment of any oral corticosteroid in the last 4 weeks and without respiratory tract infection within 8 weeks; (5) nonsmokers or ex-smokers with cessation of smoking for at least 6 months prior to the study; and (6) no history of other lung diseases, including but not limited to obliterative bronchiolitis, bronchiectasis, and cystic fibrosis. The study was approved by the Ethical Committee of the First Hospital of Shanxi Medical University. All patients were informed, and their informed consent was collected.
2.2. Detection of FeNO. FeNO was measured using a Ncoulomb expiratory analyzer (Sunvou-CA2122, China) and was performed according to the product operation instructions and American Thoracic Society/European Respiratory Society (ATS/ERS) recommendations [17]. Subjects were informed to deeply inhale NO-free air and immediately exhale in full via a mouthpiece at a constant flow rate $(50 \mathrm{~mL} / \mathrm{s})$ for $10 \mathrm{~s}$. This test was scheduled prior to pulmonary function examination.

2.3. Detection of Pulmonary Function. The determination of pulmonary function was performed using Master Screen IOS pulmonary function instrument (Jaeger Co, Germany) in strict accordance with the guidelines of ATS/ERS [18]. The pulmonary function tested in this study included respiratory function (forced expiratory volume in $1 \mathrm{~s}$ (FEV1\%), forced

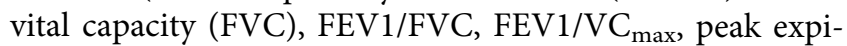
ratory flow (PEF), forced expiratory flow between $25 \%$ and $75 \%\left(\mathrm{MMEF}_{75 \% / 25 \%}\right)$, forced expiratory flow at $50 \%$ of the FVC $\left(\mathrm{FEF}_{50 \%}\right)$, forced expiratory flow at $25 \%$ of the FVC $\left(\mathrm{FEF}_{25 \%}\right)$, total lung capacity (TLC), residual volume (RV), $\mathrm{RV} / \mathrm{TLC})$, diffusion function $\left(\mathrm{D}_{\mathrm{L}} \mathrm{CO}\right)$, impulse oscillometry indexes (Fres, Z5, R5, R20, R5-R20, X5, andX20), and bronchial provocation test (PD20).

2.4. Bronchial Provocation Test (BPT). The acetylcholine was used as the provocative in BPT according to the criteria of the American Thoracic Society [19]. Subjects were asked to inhale the acetylcholine aerosol with a handheld sprayer (PARI GmbH, Germany). Isotonic saline was inhaled first as a control. This was followed by progressive doubling of concentrations of acetylcholine from low to high and the operating air flow rate was $5 \mathrm{~L} / \mathrm{min}$. The test was continued until the respiratory resistance increased to two or more times of the base level or the FEV1 had fallen $>20 \%$ or the maximal concentration of acetylcholine had been administered. The cumulative dose of acetylcholine inhaled when FEV1\% decreased by $20 \%$ (PD20) was used as quantitative index.

2.5. Statistical Analysis. SPSS 20 statistical software was used to analysis the data. The Kolmogorov-Smirnov normality test was performed to check whether continuous variables were normality distributed. Data consistent with normal distribution were expressed as mean \pm standard deviation while median (interquartile range) was used for nonnormal distribution. The two-tailed Student's T-test and Mann-Whitney $U$-tests were used to compare the differences between the two groups, while frequencies and chi-square test were used to describe the distribution of categorical variables. Pearson correlation was used for normal distribution data, and Spearman correlation analysis was used for nonnormal distribution data to determine data correlation. And the receiver operating characteristic (ROC) curve was used to analyze the diagnostic value of statistically significant indicators and combined indicators for CVA, and to 
calculate the optimal cut-off point. $P<0.05$ was considered statistically significant.

\section{Results}

3.1. The Characteristics of TA and CVA Subjects. A total of 206 subjects were included in this study, including 102 subjects with TA and 104 subjects with CVA according to the TA and CVA diagnostic criteria. All subjects were given appropriate treatment by the attending physician according to their condition, with medication as the main treatment, and all treatments were aimed at controlling the asthma condition. The asthma control test (ACT) was used to evaluate the level of asthma control in each subject after treatment. The asthma levels of most subjects were well controlled (ACT > 19), which the proportion of TA well controlled was $79.6 \%$, and the proportion of CVA well controlled was $80.1 \%$. There was no significant difference between the two groups. The basic characteristics of the subjects are shown in Table 1 . There was a significant difference in gender and age distribution between the two groups $(P<0.001)$. TA subjects were generally older than CVA subjects and mainly distributed in middle-aged and elderly people $(>45)$, while VCA subjects are evenly distributed in young people and middle-aged and elderly people. Moreover, there was no significant difference in BMI between TA and CVA subjects $(P=0.56)$.

\subsection{Comparison of Pulmonary Function between TA and CVA} Subjects. There were significant differences in pulmonary function indicators between TA and CVA subjects. All respiratory function parameters, including $\mathrm{FEV}_{1} \%, \mathrm{FVC}$, $\mathrm{FEV}_{1} / \mathrm{FVC}, \mathrm{FEV} 1 / \mathrm{VC}_{\max }, \mathrm{PEF}, \mathrm{D}_{\mathrm{L}} \mathrm{CO}$, and TLC were significantly lower $(P<0.001)$ in the TA subjects than CVA subjects (Table 2 ). Also, the PD20 was significantly lower in the TA subjects than CVA subjects $(P<0.001)$. In addition, the $\mathrm{MMEF}_{75 \% / 25 \%}, \mathrm{FEF}_{50 \%}$, and $\mathrm{FEF}_{25 \%}$, which were related to the measurement of small airway velocity, were significantly higher in CVA subjects than TA subjects. Impulse oscillometry indexes Z5, Fres, and R5-R20 in TA subjects were significantly higher than those in CVA subjects, while $\mathrm{X} 5$ and X20 in TA subjects were significantly lower than those in CVA subjects $(P<0.01)$. The FeNO value of TA subjects was significantly higher than that of CVA subjects $(P=0.007$, Figure 1$)$.

3.3. Correlations between FeNO or Small Airways Function and Other Parameters. Single correlations and multiple regression analysis of FeNO or small airways function $\left(\mathrm{MMEF}_{75 \% / 25 \%}, \mathrm{FEF}_{50 \%}, \mathrm{FEF}_{25 \%}\right)$ and the characteristics factors (sex, age, etc), pulmonary function (FEV $1_{\%} / \mathrm{FVC}$, etc), and BHR (PD20) were shown in Table 3. Single correlation and multiple regression analysis clarified the independent significant correlations of $\mathrm{MMEF}_{75 \% / 25 \%}$ with $\mathrm{FEV}_{1} / \mathrm{FVC}$, PEF, DLCO, and RV/TLC in TA subjects $(P<0.01)$ and that with $\mathrm{FEV}_{1} / \mathrm{FVC}, \mathrm{PEF}$, and RV/TLC in $\mathrm{CVA}$, and the significant correlation of $\mathrm{FEF}_{50 \%}$ with $\mathrm{FEV}_{1} /$ FVC, DLCO, and RV/TLC in TA subjects and with $\mathrm{FEV}_{1}$ /
TABle 1: The demographic characteristics of TA and CVA subjects.

\begin{tabular}{|c|c|c|c|c|}
\hline & TA $(n=102)$ & CVA $(n=104)$ & $t / \chi^{2}$ & $P$ \\
\hline \multicolumn{5}{|l|}{ Gender } \\
\hline Male & $62(60.8 \%)$ & $48(46$ & \multirow{2}{*}{4.429} & \multirow{2}{*}{$0.035^{* a}$} \\
\hline Female & $40(39.2 \%)$ & $56(53.8 \%)$ & & \\
\hline Age (year) & $58.08 \pm 11.84$ & $44.51 \pm 13.54$ & 7.61 & $<0.001^{* * * b}$ \\
\hline$<45$ & $12(1$ & $48(4$ & \multirow{2}{*}{29.501} & \multirow{2}{*}{$<0.001^{* * * a}$} \\
\hline$>45$ & $90(88.2 \%)$ & $56(53.8 \%)$ & & \\
\hline BMI $\left(\mathrm{kg} / \mathrm{m}^{2}\right)$ & $25.05 \pm 3.12$ & $25.32 \pm 3.53$ & 0.58 & $0.56^{\mathrm{b}}$ \\
\hline
\end{tabular}

CVA, cough-variant asthma; TA, typical asthma. Data were shown as mean \pm standard deviation. ${ }^{\mathrm{a}}: \chi^{2}$ test for differences between patients. ${ }^{\mathrm{b}}:$ twotailed Student's $T$-test between patients.

FVC and RV/TLC in CVA subjects, and the significant correlation of $\mathrm{FEF}_{25}$ \% with $\mathrm{FEV}_{1} / \mathrm{FVC}$, DLCO, and RV/TLC in TA subjects and with $\mathrm{FEV}_{1} / \mathrm{FVC}$ in CVA subjects. It is worth noting that in univariate analysis, there was no significant correlation between small airway function and gender or BMI, but in multivariate analysis, $\mathrm{MMEF}_{75 \% / 25 \% \text {, }}$ $\mathrm{FEF}_{50 \%}$, and $\mathrm{FEF}_{25 \%}$ in TA were significantly correlated with gender and $\mathrm{BMI}$, while $\mathrm{MMEF}_{75 \% / 25 \%}$ and $\mathrm{FEF}_{25 \%}$ were significantly correlated with gender in CVA. To some extent, gender is related to small airway function both in TA and CVA.

3.4. ROC Curves of FeNO and Small Airways Function for CVA Subjects. Significant differences of FeNO and small airways function were observed between the CVA and TA subjects, which may be potential diagnostic indicators for differentiating CVA from TA. To distinguish CVA and TA, the ROC curve (Figure 2) for these parameters were constructed to define the optimal cut-off value for the level of FeNO and small airways function. The area under the ROC curve of FeNO, $\mathrm{MMEF}_{75 \% / 25 \%}, \mathrm{FEF}_{50 \%}, \mathrm{FEF}_{25 \%}$, Fres, R5-R20, and X5 were $0.660 \quad(0.585-0.735), \quad 0.895 \quad(0.850-0.939), \quad 0.873$ (0.825-0.921), 0.898 (0.854-0.942), 0.695 (0.623-0.767), $0.650(0.575-0.725)$, and $0.645(0.570-0.720)$, respectively (Table 4). The sensitivity and specificity of FeNO in detecting CVA from TA were $90.4 \%$ and $42.2 \%$ at a cut-off point of $48.50 \mathrm{ppb}$, while the sensitivity of $\mathrm{MMEF}_{75 \% / 25 \%}, \mathrm{FEF}_{50 \%}$, $\mathrm{FEF}_{25 \%}$, Fres, R5-R20, and X5 were $78.8 \%, 80.8 \%, 84.6 \%$, $81.7 \%, 74.0 \%$, and $74.0 \%$, and specificity were $87.3 \%, 82.4 \%$, $85.3 \%, 53.9 \%, 54.9 \%$, and $49.0 \%$, respectively. Moreover, ROC analysis of FeNO combined with small airway parameters $\left(\mathrm{MMEF}_{75 \% / 25 \%}, \mathrm{FEF}_{50 \%}, \mathrm{FEF}_{25 \%}\right.$, Fres, R5-R20, or $\mathrm{X} 5)$ was performed to further enhance the value of differentiation CVA from TA (Figure 3). The AUC of FeNO combined with $\mathrm{MMEF}_{75 \% / 25 \%}$ (combine1) was 0.912 (0.873-0.952), combined with $\mathrm{FEF}_{50 \%}$ (combine2) was 0.893 (0.849-0.936), combined with $\mathrm{FEF}_{25 \%}$ (combine3) was 0.914 (0.875-0.953), combined with Fres (combine4) was 0.742 (0.673-0.810), combined with R5-R20 (combine5) was 0.707 (0.637-0.777), and combined with X5 (combine6) was 0.711 (0.640-0.782). The AUC of the combines was significantly higher than that of FeNO alone or small airway parameters FEF25\%, Fres, R5-R20, and X5 alone $(P<0.05$, Table 4$)$. It was worth noting that there was no statistically significant in 
TABLE 2: Pulmonary function test results of subjects with TA and CVA.

\begin{tabular}{lccc}
\hline & TA $(n=102)$ & CVA $(n=104)$ & $P$ \\
\hline $\mathrm{FEV}_{1} \%(\%)$ & $78.43(19)$ & $101.19(14)$ & $<0.001^{* * *}$ \\
$\mathrm{FVC}(\%)$ & $96.57 \pm 14.01$ & $106.44 \pm 10.87$ & $<0.001^{* * *}$ \\
$\mathrm{FEV}_{1} / \mathrm{FVC}$ & $70.29 \pm 6.56$ & $78.94 \pm 6.40$ & $<0.001^{* * *}$ \\
$\mathrm{FEV}_{1} / \mathrm{VCmax}$ & $68.44(9)$ & $98.81(9)$ & $<0.001^{* * *}$ \\
$\left.\mathrm{PEF}^{*} \%\right)$ & $86.09 \pm 18.75$ & $99.89 \pm 18.01$ & $<0.001^{* * *}$ \\
$\mathrm{MMEF}_{75 \% / 25 \%}(\%)$ & $40.10(17)$ & $74.40(29)$ & $<0.001^{* * *}$ \\
$\mathrm{FEF}_{50 \%}(\%)$ & $44.20(21)$ & $80.82(30)$ & $<0.001^{* * *}$ \\
$\mathrm{FEF}_{25 \%}(\%)$ & $32.42(17)$ & $61.89(28)$ & $<0.001^{* * *}$ \\
$\mathrm{PD}_{20}(\mu \mathrm{moL})$ & $0.89(2)$ & $2.52(4)$ & $<0.001^{* * *}$ \\
$\mathrm{D}_{\mathrm{L}} \mathrm{CO}$ & $82.86 \pm 19.72$ & $90.14 \pm 17.11$ & $0.005^{*}$ \\
$\mathrm{RV} / \mathrm{TLC}$ & $112.35(16)$ & $103.25(13)$ & $<0.001^{* * *}$ \\
$\mathrm{TLC}$ & $91.52 \pm 11.27$ & $96.75 \pm 9.16$ & $<0.001^{* * *}$ \\
$\mathrm{RV}$ & $101(25)$ & $102.2(19)$ & 0.451 \\
$\mathrm{Z}_{5}(\mathrm{pred})$ & $1.23(0)$ & $1.09(0)$ & $0.014^{* *}$ \\
Fres $(\mathrm{Hz})$ & $16.88(7)$ & $13.47(5)$ & $<0.001^{* * *}$ \\
$\mathrm{R} 5(\mathrm{pred})$ & $1.17(1)$ & $1.08(0)$ & 0.640 \\
$\mathrm{R} 20(\mathrm{pred})$ & $1.08(0)$ & $1.11(0)$ & 0.268 \\
$\mathrm{R} 5-\mathrm{R} 20\left(\mathrm{kPa} \cdot \mathrm{L}^{-1} \cdot \mathrm{s}^{-1}\right)$ & $0.45(1)$ & $0.34(0)$ & $<0.001^{* * *}$ \\
X5 & $-1.30(1)$ & $-1.14(1)$ & $<0.001^{* * *}$ \\
X20 & $0.25(1)$ & $0.62(0)$ & $<0.001^{* * *}$ \\
FeNO (ppb) & $45(37)$ & $27(18)$ & $0.007^{*}$ \\
\hline
\end{tabular}

CVA, cough-variant asthma; TA, typical asthma, FeNO, fractional exhaled nitric oxide; PEF, peak expiratory flow; $\mathrm{MMEF}_{75 \% / 25 \%}$, forced expiratory flow between $25 \%$ and $75 \%$; $\mathrm{FEF}_{50 \%}$, forced expiratory flow at $50 \%$ of the FVC; $\mathrm{FEF}_{25 \%}$, forced expiratory flow at $25 \%$ of the FVC; TLC, total lung capacity; RV, residual volume. Data were expressed as mean \pm standard deviation or median (interquartile range). ${ }^{*} P<0.05 ;{ }^{* *} 0.001<P<0.005$; ${ }^{* * *} P<0.001$.

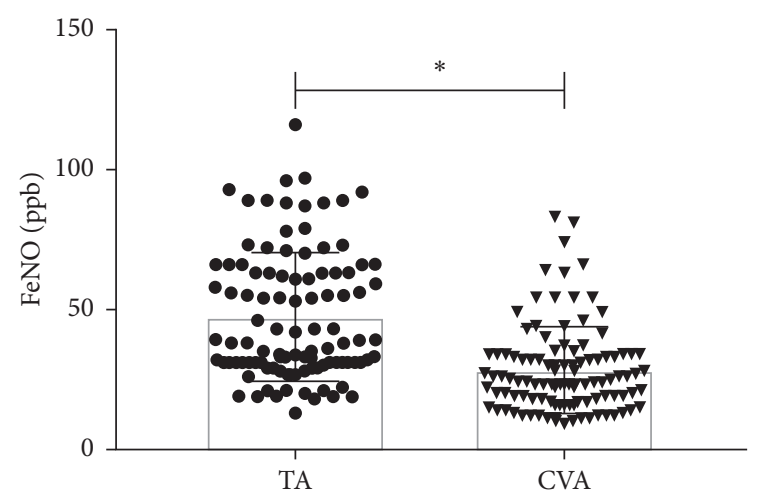

Figure 1: Comparison of FeNO level between the TA and CVA subjects, ${ }^{*} P<0.05$, compare with TA.

AUC between the combines and $\operatorname{MMEF}_{75 \% / 25 \%}(P=0.106$, Table 4$)$ or $\mathrm{FEF}_{50 \%}(P=0.085$, Table 4$)$, and the improvement was mainly in sensitivity rather than specificity.

\section{Discussion}

CVA was mainly characterized as spasm of the small airway, while the large airway was not significantly impaired. The airway inflammation of CVA was less severe than that of TA, and the lung function was manifested as changes in small airway ventilation function, while TA had varying degrees of obstruction in both large and small airways [20]. Early diagnosis and intervention are thought to be important for asthma control. In general, CVA can easily evolve into TA, and nearly $30 \%$ of patients with CVA are found to eventually develop TA, so CVA is considered to be a precursor of TA. The early diagnosis of CVA and the distinction between CVA and TA can help understand the progression of the disease and better control the disease. However, there are some limitations in the current diagnosis of CVA, and the guidelines recommend pulmonary function test and BHR test as the first-line detection [16]. However, BHR has a low utilization rate and is mostly distributed in the grade- $A$ tertiary hospitals due to its particularity [21]. Moreover, the diagnosis based on treatment effects will lead to drug abuse and difficult diagnosis $[22,23]$. In contrast, spirometry and FeNO tests are more feasible due to the advantages of safety, speed, and simplicity. In this study, FeNO and small airway function were taken as research objects to explore the diagnostic value of FENO combined with small airway indexes in distinguishing CVA and TA, so as to better understand the disease process.

FeNO can be used to assess chronic airway inflammation from central large airways to surrounding small airways [24]. In this study, it was found that FeNO levels were significantly higher in TA subjects than in CVA subjects, suggesting that TA subjects had a higher level of chronic airway inflammation than CVA subjects, which is consistent with the conclusions of previous studies [25]. The correlation analysis between FeNO and pulmonary function indexes showed that FeNO had no correlation with pulmonary function indexes. The results of this study and previous relevant studies [26] all indicated that FeNO and the severity of airflow obstruction reflected by pulmonary function were not parallel. FeNO and pulmonary function were used to evaluate asthma from the aspects of airway inflammation and airway ventilation function, respectively. In addition, the optimal diagnostic threshold of FeNO and the sensitivity and specificity of diagnosis were varied greatly in previous studies. Kowal et al. has reported that the cut-off value to distinguish a chronic cough with and without asthma was $40 \mathrm{ppb}$ with sensitivity of $88.3 \%$ and specificity of $82.6 \%$ [27]. The research of Sato et al. showed that the optimal threshold of FeNO for the diagnosis of TA and CVA in patients was $38.8 \mathrm{ppb}$ with the sensitivity of $79.2 \%$ and the specificity of $91.3 \%$ [28]. Yi et al. showed that the best cut-off point of FeNO was $33.5 \mathrm{ppb}$ with sensitivity of $69.6 \%$ and specificity of $85.1 \%$ [29], and Maniscalco et al. reported the optimal cutoff value was $33.0 \mathrm{ppb}$ with sensitivity of $92 \%$ and specificity of $88 \%$ [30]. Our study indicated a cut-off value of $48.5 \mathrm{ppb}$ with sensitivity of $90.4 \%$ and specificity of $42.2 \%$ for differentiation between CVA and TA, which obtained a higher optimal cut-off point than the previous studies. In general, FeNO had a good clinical application value and can be used to distinguish CVA and TA.

Small airway plays an important role in asthma, and there are small airway lesions in patients with asthma $[31,32]$. Similar to large airway inflammation, small airway inflammation also leads to airway wall thickening, airway narrowing, and hyperresponsiveness, which leads to poor control and frequent exacerbation of asthma [33]. In our 
TABLE 3: Correlations between FeNO or small airways function and other parameters.

\begin{tabular}{|c|c|c|c|c|}
\hline \multirow[b]{2}{*}{ a. FeNO } & \multicolumn{2}{|c|}{ Single correlation } & \multicolumn{2}{|c|}{ Multiple regression analysis } \\
\hline & & & & \\
\hline TA & $r$ & $P$ & $B$ & $P$ \\
\hline Male/female & -0.132 & 0.186 & -0.204 & 0.099 \\
\hline Age & -0.016 & 0.877 & 0.001 & 0.992 \\
\hline BMI & -0.051 & 0.611 & 0.045 & 0.704 \\
\hline $\mathrm{FEV}_{1} / \mathrm{FVC}$ & -0.140 & 0.159 & 0.047 & 0.694 \\
\hline PEF & -0.005 & 0.96 & -0.096 & 0.433 \\
\hline PD20 ( $\mu \mathrm{moL})$ & -0.023 & 0.817 & -0.096 & 0.384 \\
\hline $\mathrm{D}_{\mathrm{L}} \mathrm{CO}$ & 0.014 & 0.890 & -0.095 & 0.395 \\
\hline $\mathrm{RV} / \mathrm{TLC}$ & -0.030 & 0.763 & 0.079 & 0.483 \\
\hline CVA & $r$ & $P$ & $B$ & $P$ \\
\hline Male/female & -0.131 & 0.186 & -0.170 & 0.108 \\
\hline Age & 0.044 & 0.656 & -0.139 & 0.219 \\
\hline BMI & -0.080 & 0.422 & -0.197 & 0.055 \\
\hline $\mathrm{FEV}_{1} / \mathrm{FVC}$ & -0.153 & 0.122 & -0.067 & 0.586 \\
\hline $\mathrm{PEF}$ & -0.047 & 0.634 & 0.021 & 0.861 \\
\hline PD20 ( $\mu \mathrm{moL})$ & 0.003 & 0.976 & -0.012 & 0.906 \\
\hline $\mathrm{D}_{\mathrm{L}} \mathrm{CO}$ & 0.082 & 0.410 & -0.022 & 0.834 \\
\hline RV/TLC & 0.129 & 0.191 & 0.159 & 0.140 \\
\hline \multicolumn{5}{|l|}{ b. $\mathrm{MMEF}_{75 \% / 25 \%}$} \\
\hline TA & $r$ & $P$ & $B$ & $P$ \\
\hline Male/female & -0.158 & 0.112 & -0.199 & $0.005^{* *}$ \\
\hline Age & -0.232 & $0.019^{*}$ & -0.078 & 0.216 \\
\hline BMI & 0.050 & 0.615 & -0.226 & $0.001^{* * *}$ \\
\hline $\mathrm{FEV}_{1} / \mathrm{FVC}$ & 0.699 & $<0.001^{* * *}$ & 0.635 & $<0.001^{* * *}$ \\
\hline PEF & 0.500 & $<0.001^{* * *}$ & 0.157 & $0.025^{*}$ \\
\hline PD20 ( $\mu \mathrm{moL})$ & 0.093 & 0.351 & -0.025 & 0.683 \\
\hline $\mathrm{D}_{\mathrm{L}} \mathrm{CO}$ & 0.264 & $0.007^{* *}$ & 0.200 & $0.002^{* *}$ \\
\hline RV/TLC & -0.375 & $<0.001^{* * *}$ & 0.231 & $<0.001^{* * *}$ \\
\hline FeNO & -0.075 & 0.454 & -0.113 & 0.053 \\
\hline CVA & $r$ & $P$ & B & $P$ \\
\hline Male/female & -0.107 & 0.278 & -0.173 & $<0.001^{* * *}$ \\
\hline Age & -0.278 & $0.004^{* *}$ & 0.051 & 0.203 \\
\hline BMI & 0.048 & 0.630 & 0.008 & 0.825 \\
\hline $\mathrm{FEV}_{1} / \mathrm{FVC}$ & 0.905 & $<0.001^{* * *}$ & 0.881 & $<0.001^{* * *}$ \\
\hline PEF & 0.431 & $<0.001^{* * *}$ & 0.105 & $0.015^{*}$ \\
\hline PD20 ( $\mu \mathrm{moL})$ & 0.197 & $0.045^{*}$ & 0.025 & 0.493 \\
\hline $\mathrm{D}_{\mathrm{L}} \mathrm{CO}$ & 0.263 & $0.007^{* *}$ & 0.019 & 0.613 \\
\hline RV/TLC & -0.209 & $0.034^{*}$ & -0.092 & $0.017^{*}$ \\
\hline FeNO & -0.082 & 0.409 & 0.029 & 0.427 \\
\hline \multicolumn{5}{|l|}{ c. $\mathrm{FEF}_{50 \%}$} \\
\hline TA & $r$ & $P$ & $B$ & $P$ \\
\hline Male/female & -0.099 & 0.323 & -0.174 & $0.006^{* *}$ \\
\hline Age & -0.268 & $0.006^{* *}$ & -0.090 & 0.114 \\
\hline BMI & 0.053 & 0.599 & -0.227 & $<0.001^{* * *}$ \\
\hline $\mathrm{FEV}_{1} / \mathrm{FVC}$ & 0.810 & $<0.001^{* * *}$ & 0.717 & $<0.001^{* * *}$ \\
\hline $\mathrm{PEF}$ & 0.532 & $<0.001^{* * *}$ & 0.120 & 0.058 \\
\hline PD20 ( $\mu \mathrm{moL})$ & 0.100 & 0.318 & 0.012 & 0.831 \\
\hline $\mathrm{D}_{\mathrm{L}} \mathrm{CO}$ & 0.207 & $0.037^{*}$ & 0.179 & $0.002^{* *}$ \\
\hline RV/TLC & -0.351 & $<0.001^{* * *}$ & -0.205 & $0.001^{* * *}$ \\
\hline FeNO & -0.101 & 0.314 & -0.084 & 0.114 \\
\hline CVA & $r$ & $P$ & B & $P$ \\
\hline Male/female & -0.057 & 0.564 & -0.096 & 0.068 \\
\hline Age & -0.229 & $0.019^{*}$ & 0.088 & 0.114 \\
\hline BMI & 0.066 & 0.503 & 0.036 & 0.469 \\
\hline $\mathrm{FEV}_{1} / \mathrm{FVC}$ & 0.861 & $<0.001^{* * *}$ & 0.828 & $<0.001^{* * *}$ \\
\hline PEF & 0.460 & $<0.001^{* * *}$ & 0.101 & 0.091 \\
\hline PD20 $(\mu \mathrm{moL})$ & 0.208 & $0.034^{*}$ & 0.021 & 0.675 \\
\hline $\mathrm{D}_{\mathrm{L}} \mathrm{CO}$ & 0.202 & $0.039^{*}$ & 0.008 & 0.876 \\
\hline RV/TLC & -0.229 & $0.019^{*}$ & -0.158 & $0.003^{* *}$ \\
\hline
\end{tabular}


TABLE 3: Continued.

\begin{tabular}{|c|c|c|c|c|}
\hline \multirow[b]{2}{*}{ FeNO } & \multicolumn{2}{|c|}{ Single correlation } & \multicolumn{2}{|c|}{ Multiple regression analysis } \\
\hline & -0.127 & 0.200 & 0.007 & 0.887 \\
\hline \multicolumn{5}{|l|}{ d. FEF25\% } \\
\hline TA & $r$ & $P$ & $B$ & $P$ \\
\hline Male/female & -0.157 & 0.115 & -0.273 & $0.003^{* *}$ \\
\hline Age & -0.133 & 0.182 & -0.101 & 0.221 \\
\hline BMI & -0.054 & 0.588 & -0.363 & $<0.001^{* * *}$ \\
\hline $\mathrm{FEV}_{1} / \mathrm{FVC}$ & 0.437 & $<0.001^{* * *}$ & 0.467 & $<0.001^{* * *}$ \\
\hline PEF & 0.352 & $<0.001^{* * *}$ & 0.107 & 0.239 \\
\hline PD20 ( $\mu \mathrm{moL})$ & -0.051 & 0.609 & -0.121 & 0.139 \\
\hline $\mathrm{D}_{\mathrm{L}} \mathrm{CO}$ & 0.314 & $0.001^{* * *}$ & 0.232 & $0.006^{* *}$ \\
\hline $\mathrm{RV} / \mathrm{TLC}$ & -0.307 & $0.002^{* *}$ & -0.194 & $0.020^{*}$ \\
\hline FeNO & -0.048 & 0.631 & -0.150 & 0.051 \\
\hline CVA & $r$ & $P$ & $B$ & $P$ \\
\hline Male/female & -0.125 & 0.207 & -0.233 & $<0.001^{* * *}$ \\
\hline Age & -0.401 & $<0.001^{* * *}$ & 0.010 & 0.836 \\
\hline BMI & -0.009 & 0.926 & -0.087 & 0.052 \\
\hline $\mathrm{FEV}_{1} / \mathrm{FVC}$ & 0.900 & $<0.001^{* * *}$ & 0.888 & $<0.001^{* * *}$ \\
\hline PEF & 0.262 & $0.007^{* *}$ & -0.003 & 0.950 \\
\hline PD20 ( $\mu \mathrm{moL})$ & 0.198 & $0.044^{*}$ & 0.030 & 0.504 \\
\hline $\mathrm{D}_{\mathrm{L}} \mathrm{CO}$ & 0.288 & $0.003^{* *}$ & 0.033 & 0.465 \\
\hline RV/TLC & -0.116 & 0.240 & 0.031 & 0.510 \\
\hline $\mathrm{FeNO}$ & -0.080 & 0.422 & 0.038 & 0.390 \\
\hline
\end{tabular}

${ }^{*} P<0.05 ;{ }^{* *} 0.001<P<0.005 ;{ }^{* * *} P<0.001$.

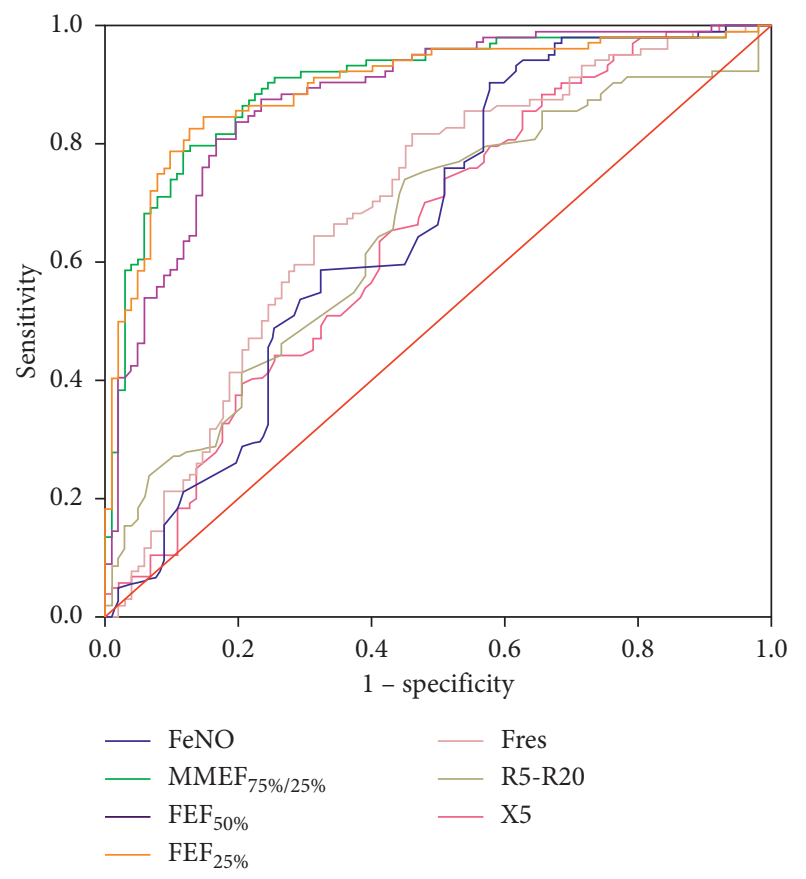

FIgURE 2: ROC curve of FeNO and small airways function indicators for CVA diagnosis.

research, the pulmonary ventilation function indexes of TA subjects were significantly lower than those of CVA subjects, indicating that the pulmonary function impairment of TA subjects was more obvious than that of CVA subjects. In addition, PD20 value in CVA subjects was higher than that in TA subjects, supporting the idea that airway reactivity of CVA was lower than that of TA $[25,26]$. The small airway flow velocity measurement indexes $\mathrm{MMEF}_{75 \% / 25 \%}, \mathrm{FEF}_{50 \%}$, $\mathrm{FEF}_{25 \%}$, and small airway resistance measurement indexes Z5, Fres, R5-R20, X5, and X20 in the CVA subjects were also significantly different from those in the TA subjects, suggesting that TA subjects not only suffer from impairment of large airway function, but also small airway function. Compared with the CVA group, TA subjects showed more severe airway remodeling degree, worse lung function and higher airway resistance. This is consistent with the results of bronchial mucosal biopsy on asthma patients [34]. In addition, correlation analysis between small airway function indicators and other pulmonary function indicators proved that small airway function indicators including $\mathrm{MMEF}_{75 \% /}$ $25 \%, \mathrm{FEF}_{50 \%}$, and $\mathrm{FEF}_{25 \%}$ were significantly positively correlated with FEV1/FVC both in CVA and TA subjects, indicating that small airway function was closely correlated to pulmonary expiratory function and can be used to evaluate asthma as airway ventilation function. However, there was no correlation between small airway function and FENO in our research. Although some studies believed that small airway function in asthma subjects was affected by airway inflammation [14], the results of this study indicated that small airway function could not be used to represent airway inflammation. Therefore, small airway function and FeNO should be combined to evaluate asthma from the perspective of pulmonary expiratory function and airway inflammation.

Our study found that both small airway function indicators and FeNO had good clinical diagnostic value for distinguishing CVA from TA. In the study of small airway function, $\mathrm{MMEF}_{75 \% / 25 \%}, \mathrm{FEF}_{50 \%}$, and $\mathrm{FEF}_{25 \%}$ are the most commonly used flow velocity measurement methods, and impulse oscillometry is the most commonly used resistance 
TABLE 4: Optimal cut-off values for the prediction of CVA.

\begin{tabular}{|c|c|c|c|c|c|}
\hline Parameter & AUC $(95 \% \mathrm{CI})$ & $P$ & Cut-off & Sensitivity (\%) & Specificity (\%) \\
\hline FeNO & $0.660(0.585-0.735)$ & $<0.001$ & 48.50 & 90.4 & 42.2 \\
\hline $\mathrm{MMEF}_{75 \% / 25 \%}$ & $0.895(0.850-0.939)$ & $<0.001$ & 60.02 & 78.8 & 87.3 \\
\hline $\mathrm{FEF}_{50 \%}$ & $0.873(0.825-0.921)$ & $<0.001$ & 63.46 & 80.8 & 82.4 \\
\hline $\mathrm{FEF}_{25 \%}$ & $0.898(0.854-0.942)$ & $<0.001$ & 45.26 & 84.6 & 85.3 \\
\hline Fres & $0.695(0.623-0.767)$ & $<0.001$ & 16.63 & 81.7 & 53.9 \\
\hline R5-R20 & $0.650(0.575-0.725)$ & $<0.001$ & 0.38 & 74.0 & 54.9 \\
\hline $\mathrm{X} 5$ & $0.645(0.570-0.720)$ & $<0.001$ & -1.32 & 74.0 & 49.0 \\
\hline Combine1 & $0.912(0.873-0.952)^{* * *}$ & $<0.001$ & - & 83.7 & 87.3 \\
\hline Combine2 & $0.893(0.849-0.936)^{* * *}$ & $<0.001$ & - & 86.5 & 83.4 \\
\hline Combine3 & $0.914(0.875-0.953)^{* * * \# \#}$ & $<0.001$ & - & 84.7 & 90.2 \\
\hline Combine 4 & $0.742(0.673-0.810)^{* \$}$ & $<0.001$ & - & 77.0 & 65.8 \\
\hline Combine5 & $0.707(0.637-0.777)^{* \&}$ & $<0.001$ & - & 71.2 & 61.8 \\
\hline Combine6 & $0.711(0.640-0.782)^{* a a}$ & $<0.001$ & - & 80.8 & 57.9 \\
\hline
\end{tabular}

Combine 1: FeNO + $\mathrm{MMEF}_{75 \% / 25 \%}$; Combine 2: FeNO + $\mathrm{FEF}_{50 \%}$; Combine 3: FeNO + FEF $25 \%$; Combine 4: FeNO + Fres; Combine 5: FeNO + R5-R20; Combine 6: FeNO + X5. ${ }^{*} P<0.05,{ }^{* *} 0.001<P<0.005,{ }^{* * *} P<0.001$, compared with FeNO; $\# P<0.05$; \#\#0.001 $<P<0.005$, compared with FEF $25 \%$; $\$ P<0.05$, compared with Fres; and $P<0.05$, compared with R5-R20; ${ }^{\text {aa }} 0.001<P<0.005$, compared with X5.

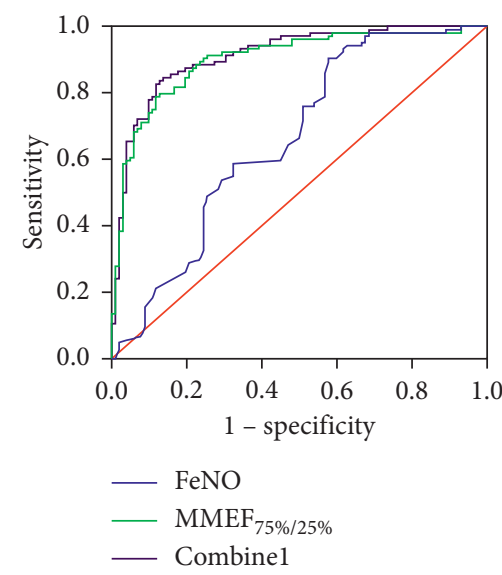

(a)

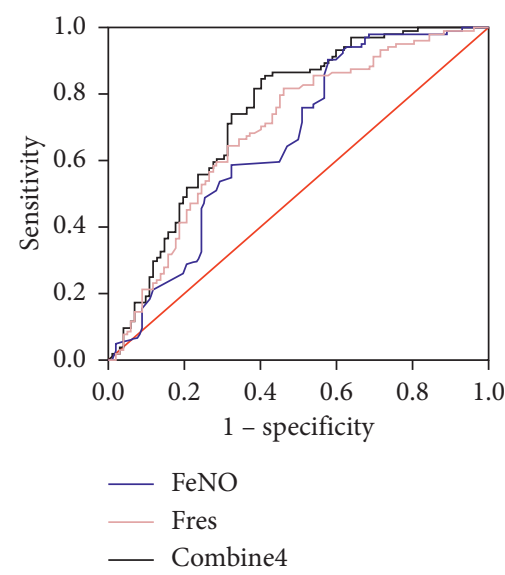

(d)

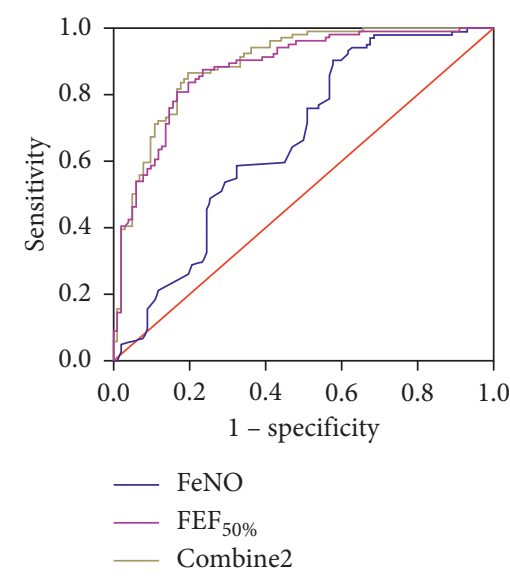

(b)

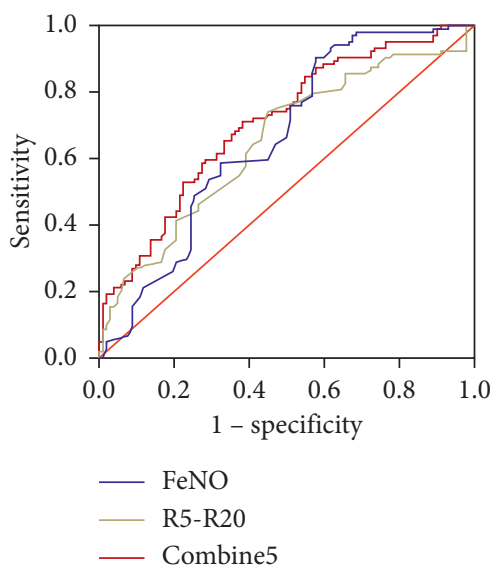

(e)
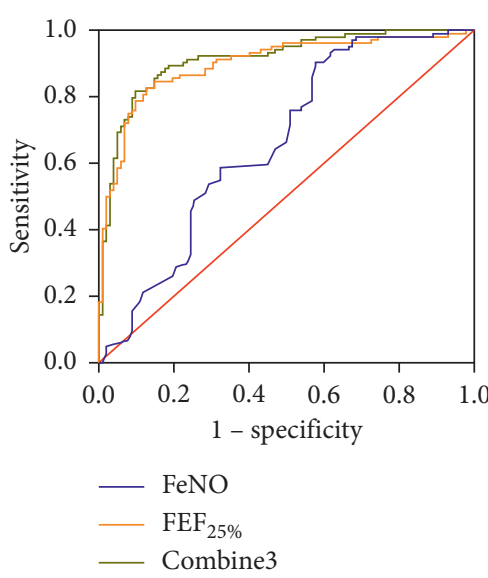

(c)

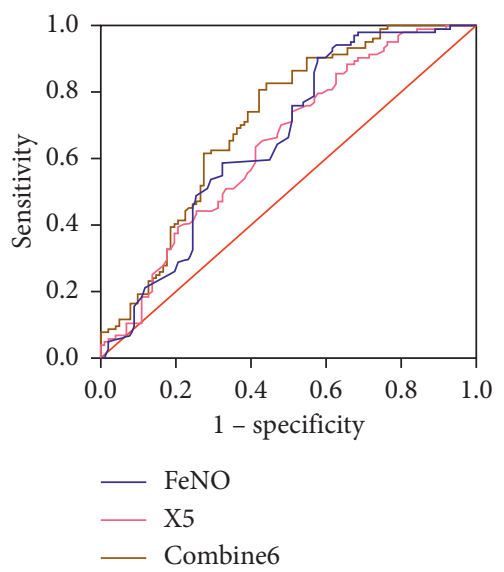

(f)

FIGURE 3: ROC curves for FeNO combined with small airways function in predicting CVA: (a) ROC curves for FeNO combined with $\mathrm{MMEF}_{75 \% / 25 \%}$, (b) ROC curves for FeNO combined with $\mathrm{FEF}_{50 \%}$, (c) ROC curves for FeNO combined with FEF $25 \%$, (d) ROC curves for FeNO combined with Fres, (e) ROC curves for FeNO combined with R5-R20, (f) ROC curves for FeNO combined with X5. Combine 1: $\mathrm{FeNO}+\mathrm{MMEF}_{75 \% / 25 \%}$, Combine 2: FeNO + $\mathrm{FEF}_{50 \%}$, Combine 3: FeNO + FEF $25 \%$, Combine 4: FeNO + Fres, Combine 5: FeNO + R5-R20, and Combine 6: FeNO + X5. 
measurement method [35]. Previous studies believed that impulse oscillometry indicators were more sensitive to reflect small airway dysfunction than conventional pulmonary ventilation function indicators [36], but in this study, $\mathrm{MMEF}_{75 \% / 25 \%}, \mathrm{FEF}_{50 \%}$, and $\mathrm{FEF}_{25 \%}$ were more sensitive to distinguish CVA from TA than impulse oscillometry indicators. Previous studies have shown that FeNO combined with impulse oscillometry indicators are helpful in diagnosis of small airway dysfunction with high sensitivity and specificity [37]. Therefore, ROC analysis of FeNO combined with small airway parameters was performed to further enhance the value of differentiation CVA from TA. The AUC of FeNO combined with small airway function indexes $\mathrm{FEF}_{25 \%}$, Fres, R5-R20, and X5 was significantly higher than the AUCs of individual indicators, while the effect of combined indicators on AUC of $\mathrm{MMEF}_{75 \% / 25 \%}$ and $\mathrm{FEF}_{50 \%}$ was not statistically significant, and the improvement was mainly in sensitivity. But in general, the diagnostic values of combined indicators were significantly superior to that of a single parameter. Airway hyperreactivity and small airway dysfunction are common characteristics of CVA and TA. The airway inflammation of CVA subjects is weaker than that of TA, and the lung function damage is less than that of TA, which indicates that CVA is the early stage of TA [38]. Since the combined indicators could significantly improve the diagnostic value, they may be helpful in the identification of CVA from TA to understand the disease better.

In conclusion, FeNO and small airway function indicators can be used to assess asthma from the two directions of airway inflammation and airway ventilation function respectively, which may be useful for distinguishing CVA from TA. The combination of FeNO and small airway function indicators reflected the pathophysiological characteristics of asthma more comprehensively, and further improved the diagnostic value of distinguishing CVA from TA.

\section{Data Availability}

The datasets used and/or analyzed during the current study are available from the corresponding author on reasonable request.

\section{Ethical Approval}

This study was performed in line with the principles of the Declaration of Helsinki and was approved by the Ethical Committee of the First Hospital of Shanxi Medical University. All patients were informed and their informed consent was collected.

\section{Conflicts of Interest}

The authors have disclosed no conflicts of interest.

\section{Authors' Contributions}

Xiaomei Kong conceived and designed the research. Yanqi Wang and Lixuan Zhao searched literature and collected the data. Fang Chen, Yufeng Guo, and Hongxia Ma analyzed the data. Baofen Han and Yijiang prepared the manuscript. Yanqi Wang, Lixuan Zhao, and Xiaomei Kong reviewed the manuscript. All the authors read and approved the final manuscript. Yanqi Wang and Lixuan Zhao have contributed equally to this article.

\section{Acknowledgments}

The authors would like to thank the First Hospital of Shanxi Medical University in China for its support to this study and patients for their participation and the hospital staff for their kind help. This work was supported by Key R \& D Projects in Shanxi Province (grant no. 201903D421072).

\section{References}

[1] P. M. Short, S. I. W. Lipworth, and B. J. Lipworth, "Relationships between airway hyperresponsiveness, inflammation, and calibre in asthma," Lung, vol. 189, no. 6, pp. 493-497, 2011.

[2] W. M. Corrao, S. S. Braman, and R. S. Irwin, "Chronic cough as the sole presenting manifestation of bronchial asthma," New England Journal of Medicine, vol. 300, no. 12, pp. 633637, 1979.

[3] L.-P. Boulet, J. M. FitzGerald, and H. K. Reddel, “The revised 2014 GINA strategy report," Current Opinion in Pulmonary Medicine, vol. 21, no. 1, pp. 1-7, 2015.

[4] M. Fujimura, H. Ogawa, Y. Nishizawa, and K. Nishi, "Comparison of atopic cough with cough variant asthma: is atopic cough a precursor of asthma?" Thorax, vol. 58, no. 1 , pp. 14-18, 2003.

[5] M. Todokoro, H. Mochizuki, K. Tokuyama, and A. Morikawa, "Childhood cough variant asthma and its relationship to classic asthma," Annals of Allergy, Asthma \& Immunology: Official Publication of the American College of Allergy, Asthma, \& Immunology, vol. 90, no. 6, pp. 652-659, 2003.

[6] L. P. Boulet, J. Milot, M. Boutet, F. St Georges, and M. Laviolette, "Airway inflammation in nonasthmatic subjects with chronic cough," American Journal of Respiratory and Critical Care Medicine, vol. 149, no. 2, pp. 482-489, 1994.

[7] A. B. Chang, P. D. Phelan, S. M. Sawyer, and C. F. Robertson, "Airway hyperresponsiveness and cough-receptor sensitivity in children with recurrent cough," American Journal of Respiratory and Critical Care Medicine, vol. 155, no. 6, pp. 1935-1939, 1997.

[8] Y. Y. Koh, J. H. Jeong, Y. Park, and C. K. Kim, "Development of wheezing in patients with cough variant asthma during an increase in airway responsiveness," European Respiratory Journal, vol. 14, no. 2, pp. 302-308, 1999.

[9] R. S. Irwin, M. H. Baumann, D. C. Bolser et al., "Diagnosis and management of cough executive summary," Chest, vol. 129, no. 1, pp. 1s-23s, 2006.

[10] Y. Nakade, M. Fujimura, N. Ohkura et al., "Reversibility of the pulmonary function based on the partial flow-volume curve predicts the efficacy of bronchodilator therapy for treating chronic cough," Internal Medicine, vol. 52, no. 18, pp. 2017-2023, 2013.

[11] R. A. Dweik, P. B. Boggs, S. C. Erzurum et al., "An official ATS clinical practice guideline: interpretation of exhaled nitric oxide levels (FENO) for clinical applications," American Journal of Respiratory and Critical Care Medicine, vol. 184, no. 5, pp. 602-615, 2011. 
[12] W.-J. Song, H. J. Kim, J.-S. Shim et al., "Diagnostic accuracy of fractional exhaled nitric oxide measurement in predicting cough-variant asthma and eosinophilic bronchitis in adults with chronic cough: a systematic review and meta-analysis," The Journal of Allergy and Clinical Immunology, vol. 140, no. 3, pp. 701-709, 2017.

[13] S. Balzar, S. E. Wenzel, and H. W. Chu, "Transbronchial biopsy as a tool to evaluate small airways in asthma," European Respiratory Journal, vol. 20, no. 2, pp. 254-259, 2002.

[14] E. Van Der Wiel, N. H. T. Ten Hacken, D. S. Postma, and M. Van Den Berge, "Small-airways dysfunction associates with respiratory symptoms and clinical features of asthma: a systematic review," The Journal of Allergy and Clinical Immunology, vol. 131, no. 3, pp. 646-657, 2013.

[15] G. I. F. Asthma, Global Strategy for Asthma Management and Prevention, Elsevier North-Holland, Amsterdam, The Netherlands, 2012.

[16] K. Lai, "Chinese national guidelines on diagnosis and management of cough: consensus and controversy," Journal of Thoracic Disease, vol. 6, no. Suppl 7, pp. S683-S688, 2014.

[17] S. American Thoracic and S. European Respiratory, "ATS/ERS recommendations for standardized procedures for the online and offline measurement of exhaled lower respiratory nitric oxide and nasal nitric oxide, 2005," American Journal of Respiratory and Critical Care Medicine, vol. 171, no. 8, pp. 912-930, 2005.

[18] M. R. Miller, J. Hankinson, V Brusasco et al., "Standardisation of spirometry," European Respiratory Journal, vol. 26, no. 2, pp. 319-338, 2005.

[19] "Standards for the diagnosis and care of patients with chronic obstructive pulmonary disease (COPD) and asthma. This official statement of the American Thoracic Society was adopted by the ATS Board of Directors, November 1986," American Review of Respiratory Disease, vol. 136, no. 1, pp. 225-244, 1987.

[20] A. Niimi, "Cough variant asthma," Nihon Rinsho Japanese Journal of Clinical Medicine, vol. 74, no. 10, pp. 1693-1697, 2016.

[21] J. Zheng, "A nationwide questionnaire survey on clinical application of pulmonary function testing in China," Zhonghua Jiehe He Huxi Zazhi, vol. 25, no. 2, pp. 69-73, 2002.

[22] B. P. Ponsioen, W. C. Hop, N. A. Vermue, P. N. Dekhuijzen, and A. M. Bohnen, "Efficacy of fluticasone on cough: a randomised controlled trial," European Respiratory Journal, vol. 25, no. 1, pp. 147-152, 2005.

[23] S. Hamada, Y. Ito, S. Imai, T. Oguma, A. Niimi, and M. Mishima, "Effect of inhaled corticosteroid therapy on CT scan-estimated airway dimensions in a patient with chronic bronchitis related to ulcerative colitis," Chest, vol. 139, no. 4, pp. 930-932, 2011.

[24] M. Munakata, "Exhaled nitric oxide (FeNO) as a non-invasive marker of airway inflammation," Allergology International, vol. 61, no. 3, pp. 365-372, 2012.

[25] T. Shimoda, Y. Obase, R. Kishikawa, T. Iwanaga, A. Miyatake, and S. Kasayama, "The fractional exhaled nitric oxide and serum high sensitivity C-reactive protein levels in cough variant asthma and typical bronchial asthma," Allergology International, vol. 62, no. 2, pp. 251-257, 2013.

[26] M. Fujimura, N. Ohkura, M. Abo et al., "Exhaled nitric oxide levels in patients with atopic cough and cough variant asthma," Respirology, vol. 13, no. 3, pp. 359-364, 2008.

[27] K. Kowal, A. Bodzenta-Lukaszyk, and S. Zukowski, "Exhaled nitric oxide in evaluation of young adults with chronic cough," Journal of Asthma, vol. 46, no. 7, pp. 692-698, 2009.
[28] S. Sato, J. Saito, Y. Sato et al., "Clinical usefulness of fractional exhaled nitric oxide for diagnosing prolonged cough," Respiratory Medicine, vol. 102, no. 10, pp. 1452-1459, 2008.

[29] F. Yi, R. Chen, W. Luo et al., "Validity of fractional exhaled nitric oxide in diagnosis of corticosteroid-responsive cough," Chest, vol. 149, no. 4, pp. 1042-1051, 2016.

[30] M. Maniscalco, S. Faraone, M. Sofia, A. Molino, A. Vatrella, and A. Zedda, "Extended analysis of exhaled and nasal nitric oxide for the evaluation of chronic cough," Respiratory Medicine, vol. 109, no. 8, pp. 970-974, 2015.

[31] J. Cohen, D. S. Postma, W. R. Douma, J. M. Vonk, A. H. De Boer, and N. H. T. Ten Hacken, "Particle size matters: diagnostics and treatment of small airways involvement in asthma," European Respiratory Journal, vol. 37, no. 3, pp. 532-540, 2011.

[32] E. Van Der Wiel, D. S. Postma, T. Van Der Molen, L. Schiphof-Godart, N. H. T. Ten Hacken, and M. Van Den Berge, "Effects of small airway dysfunction on the clinical expression of asthma: a focus on asthma symptoms and bronchial hyper-responsiveness," Allergy, vol. 69, no. 12, pp. 1681-1688, 2014.

[33] M. K. Tulic, P. Christodoulopoulos, and Q. Hamid, "Small airway inflammation in asthma," Respiratory Research, vol. 2, no. 6, pp. 333-339, 2001.

[34] A. Niimi, H. Matsumoto, M. Minakuchi, M. Kitaichi, and R. Amitani, "Airway remodelling in cough-variant asthma," The Lancet, vol. 356, no. 9229, pp. 564-565, 2000.

[35] M. Van Den Berge, N. H. T. Ten Hacken, J. Cohen, W. R. Douma, and D. S. Postma, "Small airway disease in asthma and COPD," Chest, vol. 139, no. 2, pp. 412-423, 2011.

[36] N. Naji, E. Keung, J. Kane, R. M. Watson, K. J. Killian, and G. M. Gauvreau, "Comparison of changes in lung function measured by plethymography and IOS after bronchoprovocation," Respiratory Medicine, vol. 107, no. 4, pp. 503-510, 2013.

[37] L. Liu, W. Liu, C. Liu et al., "Study on small airway function in asthmatics with fractional exhaled nitric oxide and impulse oscillometry," The clinical respiratory journal, vol. 12, no. 2, pp. 483-490, 2018.

[38] M. Fujimura, "Pathophysiology, diagnosis and treatment of cough variant asthma," Rinsho byori The Japanese Journal of Clinical Pathology, vol. 62, no. 5, pp. 464-470, 2014. 